\title{
Correlation between total air pollutant emissions and incidence of type 1 diabetes in the Russian Federation
}

\author{
Hoon Sung Choi, $\mathrm{MD}^{1,{ }^{*}}$, Jin Taek Kim, MD ${ }^{2,}{ }^{*}$, Ji-Young Seo, $\mathrm{MD}^{3}$, Faina Linkov, PhD, MPH ${ }^{4}$, Evgeniy Shubnikov, MD ${ }^{5}$, Hong \\ Kyu Lee, $\mathrm{MD}^{2}$ \\ ${ }^{1}$ Department of Internal Medicine, Kangwon National University School of Medicine, Chuncheon, Korea; ${ }^{2}$ Department of Internal Medicine, Eulji General Hospital, \\ Eulji University School of Medicine, Seoul, Korea; ${ }^{3}$ Department of Pediatrics, Eulji General Hospital, Eulji University School of Medicine, Seoul, Korea; ${ }^{4}$ Department \\ of Health Administration and Public Health, Rangos School of Health Sciences, Duquesne University, Pittsburgh, PA, USA; ${ }^{5}$ Center for Endocrinology "SibDiab", \\ Novosibirsk, Russian Federation
}

Background: Exposure to air pollution (gaseous pollutants and/or particulate matter) has been associated with the incidence, prevalence, and mortality of type 1 diabetes (T1D).

Purpose: To examine the quantitative relationship between air pollutant emissions and the incidence of T1D.

Methods: We examined the association between the incidence of T1D and type 2 diabetes (T2D) in 2017 as well as that of T1D in patients younger than 15 years in 2016 with "emissions of air-polluting substances from stationary and mobile sources by regions of the Russian Federation in 2016" as reported by the Federal Diabetes Register of Russia downloaded from the Russian government website (http://www.mnr.gov.ru/docs/ gosudarstvennye_doklady/o_sostoyanii_i_ob_okhrane okruzhayushchey_sredy_rossiyskoy_federatsii).

Results: The incidence of T1D across all ages in each region of the Russian Federation correlated with the total air pollutants emitted in the region each year $(r=0.278, P=0.013)$. The incidence of T2D was also correlated with the amount of air pollutants $(r=0.234, P=0.037)$ and the incidence of T1D $(r=0.600, P<0.001)$ in each country. Similarly, the incidence of T1D in patients younger than 15 years correlated with the total air pollutants emitted each year in each region $(r=0.300$, $P=0.011$ ).

Conclusion: The quantitative relationship between the total air pollutants emitted and the incidence of T1D and T2D in the Russian Federation suggests that air pollution contributes to the development of T1D and T2D.

Key words: Air pollution, Incidence, Type 1 diabetes

\section{Key message}

Question: Is there a quantitative relationship between air pollutant emissions and the incidence of type 1 diabetes (T1D)?

Finding: The incidence of T1D in each region of the Russian
Federation correlated with the total air pollutants emitted each year.

Meaning: These findings suggest that air pollution contributes to the development of T1D.

\section{Introduction}

Type 1 diabetes (T1D) is an autoimmune disease, in which the immune system destroys insulin-producing pancreatic beta cells. The causes of T1D remain mostly unknown, although genetic factors, especially the human leukocyte antigen (HLA) class II gene haplotypes, are known to exert a strong influence. ${ }^{1)}$ Epidemiologic studies have revealed that environmental factors, such as viruses, nutrition, toxic agents, and socioeconomic and psychosocial factors, also play important roles. ${ }^{2,3)}$ Nongenetic factors are believed to play important roles in the T1D epidemic because the majority of genetically predisposed individuals do not develop T1D, and the incidence of T1D has been rising worldwide. $^{4)}$

Type 2 diabetes (T2D) is considered a different disease, characterized by insulin resistance, rather than the autoimmunity of T1D. However, the distinction between the 2 diseases has become blurred, as many T1D cases show insulin resistance, and several T2D patients have anti-islet antibodies, making the socalled "double diabetes" a reality. ${ }^{5)}$

One of the well-published epidemiological patterns suggests a higher incidence of T1D in the northern countries, such as Finland and Canada, than that in the southern countries, such as Italy and Spain. $\left.{ }^{6}\right)$ However, there are exceptions; Sardinia has a high incidence of T1D, even though it is located in the Mediterranean Sea, and some of the regions bordering Finland have much lower rates than Finland. ${ }^{7,8}$ Other countries located in the south have recently emerged as new hotspots, namely,

Corresponding author: Hong Kyu Lee, MD. Department of Internal Medicine, Eulji General Hospital, Eulji University School of Medicine, 68 Hangeulbiseok-gil, Nowon-gu, Seoul 01830, Korea

凶Email: hongkyu414@gmail.com, https://orcid.org/0000-0002-4926-0984

*These authors contributed equally to this study as co-first authors.

Received: 3 September, 2020, Revised: 21 December, 2020, Accepted: 31 December, 2020

This is an open-access article distributed under the terms of the Creative Commons Attribution Non-Commercial License (http://creativecommons.org/licenses/by$\mathrm{nc} / 4.0 /$ ) which permits unrestricted non-commercial use, distribution, and reproduction in any medium, provided the original work is properly cited.

Copyright (c) 2021 by The Korean Pediatric Society 
Kuwait ${ }^{9)}$ and Saudi Arabia. ${ }^{9}{ }^{90)}$ The Bashkortostan Republic of the Russian Federation is another hotspot, despite its location in southern Russia, where the incidence is generally low. ${ }^{11)}$

These regions are notorious for their burgeoning oil industries. We suspect the possibility that air pollution from the oil industry is involved. The use of coal may play a similar role in Sardinia, which is famous for its long history of coal mining. We speculate that coal burning to warm houses is also responsible for the high incidence of T1D in northern countries.

Exposure to air pollution (gaseous pollutants and/or particulate matter) has been associated with the incidence, prevalence, and mortality of T1D in children. ${ }^{12)}$ The association between air pollution and diabetes is even stronger for T2D in adults than it is for T1D. ${ }^{13,14)}$ However, a few studies have examined the role of air pollutants in the development of T1D, and the results have not been conclusive. ${ }^{15-17)}$ Since T1D is a rare disease, and a myriad of chemicals are potentially involved, difficulties in accurately estimating the exposure to air pollution and establishing the relationship between the exposure and T1D incidence could have hindered the establishment of a firm conclusion. Di Ciaula ${ }^{15)}$ reported that such a relationship exists in Apulia, South Italy; T1D incidence was significantly and positively correlated with mean yearly levels of particulate matter particles $\leq 10 \mathrm{~mm}$ in aerodynamic diameter $\left(\mathrm{PM}_{10}\right)$, but not with ozone, $\mathrm{NO}_{\mathrm{x}}$, and CO levels in the whole population.

We were encouraged by recent scientific advances in the role of environmental pollutants on the immune system, clinical experiences made from immune checkpoint inhibitor (ICI) therapy, which were complicated with autoimmune disorders including T1D and observations made in the newly recognized fulminant T1D. ${ }^{18)}$ Polluted air has been shown to affect humoral and cellular immune responses and may be one of the accelerating cofactors in beta-cell destruction, leading to T1D. ${ }^{19,20)}$ These observations suggest a mechanism by which air pollution could induce T1D. We hypothesized that if there is an association between T1D incidence and air pollution, such an association could be observed at global level or in a large country, where the incidence of T1D significantly varies by region and is reported in a standardized way, and the emissions of pollutants into air are measured using standardized methods. We noted that the Russian Federation had been maintaining standardized registries on diabetes and had also been measuring the total annual emission of pollutants into the air across their 86 countries and regions since the 1990s. As the role of air pollution on the incidences of T1D and T2D in Russia had not been explored in previously published literature, we investigated the association between the total emission of air pollutants and the incidences of T1D and T2D across the Russian Federation.

\section{Methods}

\section{Data sources}

Data on the 2017 incidences of T1D and T2D across all age groups in Russian Federation countries were obtained from Supplement 2 of a paper published by Dedov et al. and data on the 2016 incidences of T1D and all types of diabetes in children aged below 15 years were obtained from Supplement 1 of another paper by Dedov et al. ${ }^{11,21)}$ They used data from the Federal Diabetes Register (http://diaregistry.ru/content/oproekte.html\# content) of Russia. This registry was established in 1996 by the Russian Federation's Ministry of Health as Federal Target Program "Sugar diabetes" (order no. 404). Since 2014, it has been transformed into a single electronic database. By 2017, it had included most of the Russian Federation regions (81 regions), making it possible to monitor the prevalence of diabetes and diabetic complications in the Russian Federation. Dedov et al. used this database to calculate the total number of children and adolescents with diabetes in the Russian Federation as of December 31, 2016. They used the populations of the Russian Federation regions, according to the Federal State Statistics Service (Rosstat), to calculate the incidence and prevalence per 100,000 children and adolescents. Incidence is defined as the number of new cases first reported in the current calendar year per 100,000 people in the appropriate age group.

Individuals were diagnosed with diabetes if one or more of the following criteria, adapted from the 2009 American Diabetes Association criteria, were met: fasting glucose level $\geq 7.0 \mathrm{mmol} / \mathrm{L}$, postchallenge 2-hour glucose level $\geq 11.1 \mathrm{mmol} / \mathrm{L}$, hemoglobin A1c $\geq 6.5 \%$, or current use of antidiabetic medications. ${ }^{22)}$ The criteria for diagnosing T1D followed international recommendations, and the date of diagnosis was considered to be the date of the first insulin injection. ${ }^{23,24)}$ For the total quantity of pollutants emitted into the air, we used "emissions of air-polluting substances from stationary and mobile sources by regions of the Russian Federation in 2016" (original in Russian), downloaded from the website run by the Russian government (http://www. mnr.gov.ru/docs/gosudarstvennye_doklady/o_sostoyanii_i_ob_ okhrane_okruzhayushchey_sredy_rossiyskoy_federatsii/). "emissions of air-polluting substances" is an emission inventory, which lists the amount of pollutants from all sources entering the air in a given time period, within the boundaries of a fixed area. ${ }^{25)}$ These include $\mathrm{CO}, \mathrm{NO}_{\mathrm{x}}, \mathrm{SO}_{\mathrm{x}}$, particulate matter (PM), volatile organic compounds, and $\mathrm{NH}_{3}$. This study used publicly available information and did not collect or record personally identifiable information regarding the subjects. Furthermore, it was exempted from institutional review board review.

\section{Statistical analysis}

We hypothesized that the relationship between total pollutant emission of air-polluting substances into the air in each region and the incidence of T1D in that region is linear. We also assumed that the incidence of T1D in 2017 and that in 2016 were not significantly different. Using Pearson correlation coefficient, we evaluated the association of T1D and T2D incidence with the total emission of air-polluting substances in 2016 in each region. Because the distribution of the total emission of airpolluting substances was skewed to the right, it was converted to 
logarithmic base 2. We also compared the incidence of diabetes according to tertiles of the amount of air-pollutant emissions in 84 Russian Federation regions using 1-way analysis of variance. Statistical analyses were performed using IBM SPSS Statistics ver. 21.0 (IBM Co., Armonk, NY, USA). $P<0.05$ was considered statistically significant.

\section{Results}

The incidences of T1D in 2017, T1D in patients aged 0-14 years in 2016, and T2D in 2017 were 7, 14.2, and 185.2, respectively, per 100,000 population in the Russian Federation. Table 1 shows the correlation matrix between diabetes incidence

Table 1. Correlation matrix of the incidence of diabetes and the total air pollutants emitted in the 84 regions of the Russian Federation in 2016

\begin{tabular}{llc}
\hline Variable & Value & $\begin{array}{c}\text { Emissions (tons) of air } \\
\text { pollutants by regions }\end{array}$ \\
\hline T1D (all ages) (in 2017) & Pearson $r$ & 0.278 \\
& $P$ value & 0.013 \\
T1D (age $\leq 14)$ (in 2016) & Pearson $r$ & 0.300 \\
& $P$ value & 0.011 \\
T2D (in 2017) & Pearson $r$ & 0.234 \\
& $P$ value & 0.037 \\
\hline
\end{tabular}

The air pollutant emission amounts were transformed by logarithm with base 2 .

T1D, type 1 diabetes; T2D, type 2 diabetes. and the amount of air pollutants in the 84 regions of the Russian Federation. The incidence of T1D in all ages showed a positive correlation with the amount of air pollutants emitted each year $(r=0.278, P=0.013)$. T2D also showed a positive correlation with the amount of air pollutants $(r=0.234, P=0.037)$. The association between T1D incidence and T2D incidence also showed positive correlation $(r=0.600, P<0.001)$. In patients below the age of 15 , the incidence of T1D correlated with the amount of air pollutants $(r=0.300, P=0.011)$. Table 2 shows the different incidence rates of T1D and T2D according to the tertiles of the amount of air-pollutant emissions in the 84 Russian Federation regions. The incidence of diabetes and emissions of air pollutants according to each Russian Federation region are shown in Supplementary Table 1. Fig. 1 shows a significant correlation between diabetes incidences and the total emission of air pollutants in the 84 Russian Federation regions. Fig. 2 shows the geometric mapping of diabetes incidences and the amount of air-pollutant emissions in the 84 Russian Federation regions.

\section{Discussion}

This study shows for the first time that there are quantitative relations between the total amounts of pollutants emitted into the air and the incidence of childhood diabetes, both T1D and T2D, in each region or country in the Russian Federation. Although the correlation coefficients were not very high, they were significant. We expected weak correlations between air pollution

Table 2. Comparison of the incidence of diabetes by air pollutant emission tertile of the 84 regions of Russian Federation in 2016

\begin{tabular}{lcccc}
\hline Variable & 1st tertile & 2nd tertile & 3th tertile & $P$ value \\
\hline Emission (tons) & $6.3 \pm 0.8$ & $7.8 \pm 0.4$ & $9.5 \pm 0.7$ & $<0.001$ \\
T1D (age<15) (in 2017) & $12.6 \pm 7.4$ & $13.0 \pm 7.7$ & $16.5 \pm 5.4$ & 0.087 \\
T1D (all ages) (in 2016) & $6.4 \pm 3.2$ & $7.5 \pm 3.2$ & $8.5 \pm 2.2$ & 0.033 \\
T2D (in 2017) & $164.8 \pm 72.4$ & $211.4 \pm 77.8$ & $204.2 \pm 54.7$ & $\mathbf{0 . 0 3 4}$ \\
\hline
\end{tabular}

Values are presented as mean \pm standard deviation and compared using 1-way analysis of variance. The air pollutant emission amounts were transformed by logarithm with base 2 .

T1D, type 1 diabetes; T2D, type 2 diabetes.

Boldface indicates a statistically significant difference with $P<0.05$.

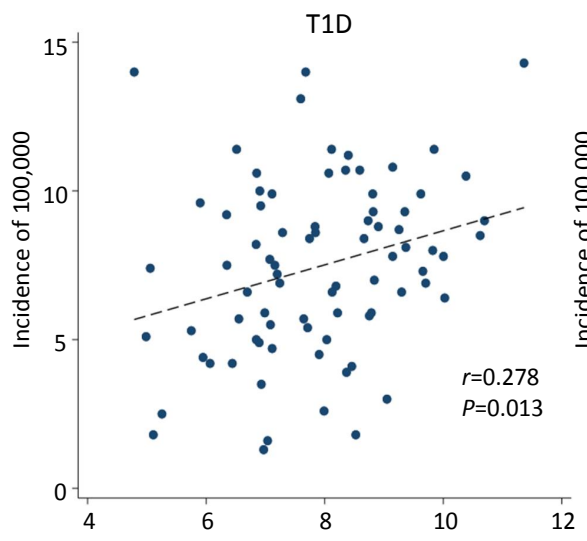

A Log-transformed amount of air pollutants

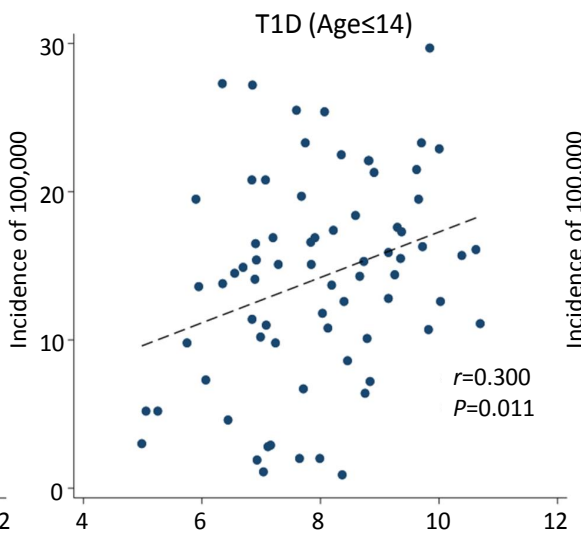

B Log-transformed amount of air pollutants

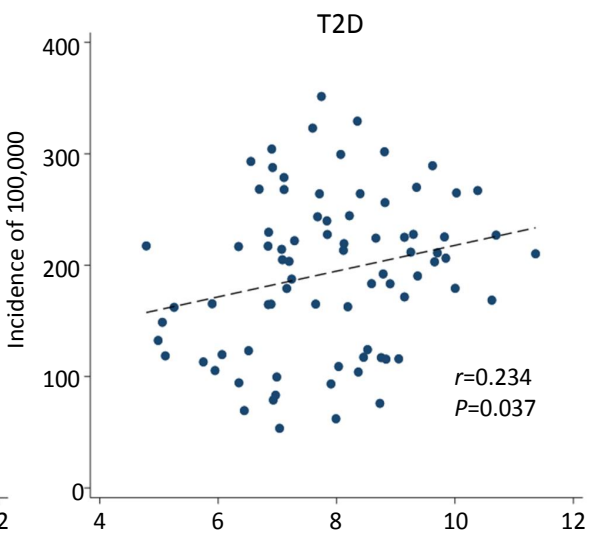

C Log-transformed amount of air pollutants

Fig. 1. Correlation between diabetes incidence and air pollutant emission amounts. The air pollutant emission amounts were transformed by logarithm with base 2. (A) Type 1 diabetes mellitus (T1DM), (B) T1DM (age $\leq 14)$, (C) type 2 diabetes mellitus. 


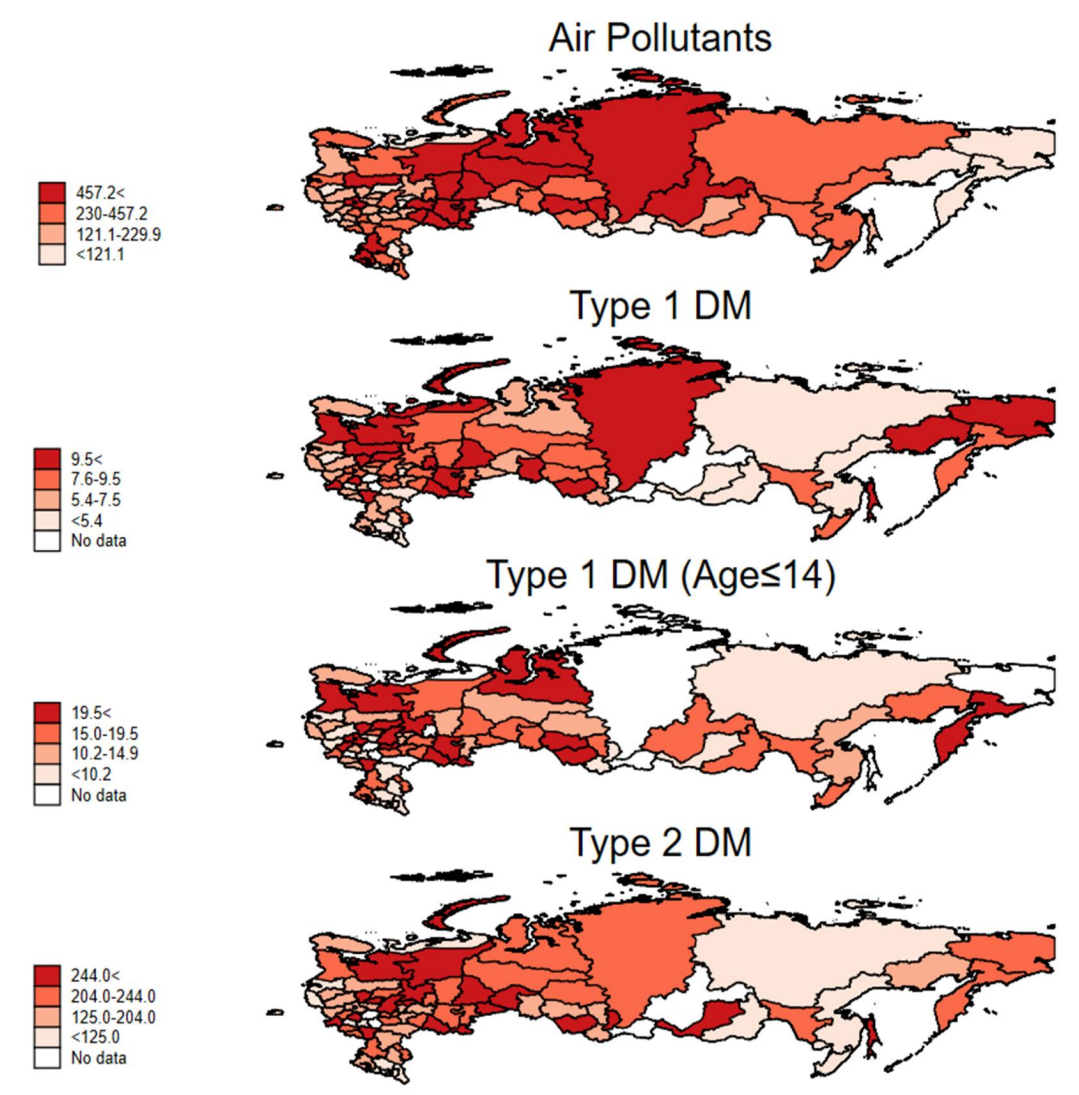

Fig. 2. Geometric mapping of diabetes incidence and air pollutant amounts of the 84 regions of the Russian Federation. Lighter areas are those with lower incidence (pollutant amount), while darker areas are those with higher incidence (pollutant amount). DM, diabetes mellitus.

and T1D incidence, if any, as the pollutants in the air would act in combination with other correlates, such as socioeconomic status, ethnic differences, well-known HLA class II genes, and other factors. ${ }^{1-3)}$ We investigated the roles of environmental factors because the incidence of T1D has been increasing rather rapidly, a phenomenon that has been difficult to explain using genetic factors alone ${ }^{4)}$ We suspected air pollutants because the incidence maps of T1D in children revealed several hotspot countries and regions notorious for their burgeoning oil industries, namely, Kuwait, Saudi Arabia, Bashkortostan, and the Yaroslavl regions of the Russian Federation. We further suspected that coal might have played a similar role in Sardinia, Italy.

We identified a few very recent reports supporting our results; Hathout et al. ${ }^{12}$ r reported on evidence suggesting that cumulative exposure to ozone, $\mathrm{O}_{3}$, and sulfate in ambient air may predispose children to the development of T1D. In a retrospective, population-based cohort study from Ontario, Canada, Elten et al. ${ }^{26)}$ also showed that exposure to $\mathrm{O}_{3}$ during a critical period of development was associated with an increased risk of pediatric diabetes incidence up to 6 years of age. In Bavaria, Germany, exposure to high levels of $\mathrm{PM}_{10}$ and $\mathrm{NO}_{2}$ was associated with a shift in the 10th percentile of the age of T1D diagnosis to lower values, suggesting their role in accelerating disease manifestation. ${ }^{16)}$ There may be other mechanisms. During a systemic study on the environmental factors predicting islet cell antibody (ICA) seroconversion among healthy schoolchildren in Lithuania, Skrodeniene et al. ${ }^{27)}$ found that more than half of the ICA-positive children lived in homes where family members were smoking indoors, while indoor smoking was recorded only for a quarter of controls. There are several other reports that link maternal exposure to tobacco smoking, as summarized by Bodin et al. ${ }^{2}$ However, the overall association between exposure to air pollutants and development of T1D was inconclusive. It was difficult to reconcile, for example, the fact that air pollution in European countries is decreasing while the incidence of T1D is increasing at the same time.,28) Therefore, if air pollution does play a role, a certain chemical component of air pollutants or complex interactions between the pollutants, not air pollution itself, should be suspected. In this regard, a report by Skrodeniene et al. ${ }^{27)}$ provides a clue; an increased prevalence of ICA positivity was noted among children living in homes where family members smoked, suggesting that chemicals produced during tobacco smoking might have been linked to T1D. In fact, Wang et al. ${ }^{29)}$ reported that toxic chemicals, such as benzo(a) pyrene $(\mathrm{BaP})$, produced during smoking enter the lungs and induce autoimmunity directed to pancreatic islets.

Recent observations made during clinical studies with ICI, which block the programmed cell death protein-1 (PD-1)/programmed death ligand-1 (PD-L1) pathway, suggest that certain chemicals may cause T1D. ${ }^{18)}$ ICI therapy-induced typical clinical features of T1D, with positive serum autoantibodies against glutamic acid decarboxylase 65 , islet antigen 2 , and insulin in 
their sera. Evidence from these clinical studies is particularly relevant because Wang et al. ${ }^{29)}$ reported that tobacco smoke and the carcinogenic BaP induce PD-L1 expression in lung epithelial cells in vitro and in vivo, a process mediated by the aryl hydrocarbon receptor (AhR). Thus, it is plausible that pollutants in the air, such as $\mathrm{BaP}$ and polychlorinated biphenyls, increase PD-L1 expression by activating AhR, priming the body to react to these chemicals. T1D or autoimmune diseases occur when the immune system, particularly $\mathrm{T}$ cells, responds excessively, as evidenced by ICI treatment. Another observation in clinical diabetes adds further insight into these complicated interactions between pollutants, AhR, the PD-1/PD-L1 pathway, and the immune system; class 2 HLA molecules were found to be strongly associated with fulminant T1D, in which antiICAs are mostly negative. ${ }^{30)}$ These studies suggest that both air pollution and indoor pollution, such as indoor smoking and exogenous chemicals like drugs, may be critically involved in T1D development. These observations also suggest that the interaction between the chemicals in air and genetic susceptibility are important in determining the clinical features of diabetes.

In this study, the incidence of T2D also correlated with the total amount of pollutants emitted. This finding is consistent with a recent review on the association between air pollution and T2D, although the methods employed in the studies reviewed are quite different from those in the Russian Register. ${ }^{31-33)}$ The fact that T2D incidence is also related to the amount of airpollutant production suggests a partial explanation for the high correlation between T1D incidence and T2D incidence in our study. In a previous report, Tuomi et al. ${ }^{32)}$ highlighted that diabetes is a much more heterogeneous disease than the current classification portrays, in which it is either T1D or T2D, and the current classification system probably represents 2 extremes. The presence of double or hybrid diabetes was proposed. ${ }^{5)}$ Many patients have a genetic predisposition to both types of diabetes, leading to a hybrid form of diabetes (e.g., latent autoimmune diabetes in adults). Furthermore, evidence is rapidly accumulating that $\mathrm{PM}_{2.5}$ (smaller-sized air-polluting particles) is an important attributable factor for T2D. ${ }^{33,34)}$ Historically, the first recognizable report on T1D described the disease as a condition presenting in children or young adults and terminating in fatal ketoacidosis; thus, a hardly recognizable clinical entity appeared in the literature only towards the end of the 19th century. ${ }^{35)}$ As the use of coal markedly increased during industrialization, there is historical plausibility that air pollution from coal burning was one of the factors influencing the development of T1D.

There are some limitations to this study. Due to the limited availability of data, it was not possible to analyze the relationship between T1D incidence and air-pollutant emissions in the same year. However, the air pollutant survey was conducted in 2016 and preceded the 2017 diabetes investigation, which suggests some of the causal effects. Stratified analysis based on other clinical characteristics, such as age and sex, was not performed for the same reason. In addition, we could not control the race/ ethnicity factor for T1D and obesity for T2D.
In conclusion, quantitative relations between the total amount of pollutants emitted into the air and the incidence of T1D in regions and countries in the Russian Federation as well as recent observations on autoimmune diabetes induced by chemicals and fulminant diabetes suggest that air pollution is likely to be one of several factors that influence the development of T1D. However, the present study is a cross-sectional study, and there is a limit to the conclusion of the causal relationship. It is necessary to conduct further studies with multinational study groups based on the results of this pilot study. It will also be worthwhile to conduct a well-designed prospective study that measures exposure to air pollution. For example, the impact of $\mathrm{PM}_{2.5}$ and concentrations of individual chemicals on the development of T1D in genetically susceptible subjects can be studied using sophisticated methods.

\section{Footnotes}

Conflicts of interest: No potential conflict of interest relevant to this article was reported.

Supplementary material: Supplementary Table 1 can be found via https://doi.org/ 10.3345/cep.2020.01501.

ORCID:

Hong Kyu Lee @ https://orcid.org/0000-0002-4926-0984

\section{References}

1. Pociot F, Lernmark A. Genetic risk factors for type 1 diabetes. Lancet 2016;387:2331-9.

2. Bodin J, Stene LC, Nygaard UC. Can exposure to environmental chemicals increase the risk of diabetes type 1 development? Biomed Res Int 2015;2015:208947.

3. Butalia S, Kaplan GG, Khokhar B, Rabi DM. Environmental risk factors and type 1 diabetes: past, present, and future. Can J Diabetes 2016;40:586-93.

4. Tuomilehto J. The emerging global epidemic of type 1 diabetes. Curr Diab Rep 2013;13:795-804.

5. Khawandanah J. Double or hybrid diabetes: a systematic review on disease prevalence, characteristics and risk factors. Nutr Diabetes 2019; 9:33.

6. Patterson C, Guariguata L, Dahlquist G, Soltesz G, Ogle G, Silink M. Diabetes in the young - a global view and worldwide estimates of numbers of children with type 1 diabetes. Diabetes Res Clin Pract 2014;103:16175 .

7. Songini M, Lombardo C. The Sardinian way to type 1 diabetes. J Diabetes Sci Technol 2010;4:1248-55.

8. Borchers AT, Uibo R, Gershwin ME. The geoepidemiology of type 1 diabetes. Autoimmun Rev 2010;9:A355-65.

9. Shaltout AA, Wake D, Thanaraj TA, Omar DM, Al-AbdulRazzaq D, Channanath A, et al. Incidence of type 1 diabetes has doubled in Kuwaiti children 0-14 years over the last 20 years. Pediatr Diabetes 2017;18:7616.

10. Robert AA, Al-Dawish A, Mujammami M, Dawish MAA. Type 1 diabetes mellitus in Saudi Arabia: a soaring epidemic. Int J Pediatr 2018;2018:9408370.

11. Dedov II, Shestakova MV, Peterkova VA, Vikulova OK, Zheleznyakova 
$\mathrm{AV}$, Isakov MA, et al. Diabetes mellitus in children and adolescents according to the Federal diabetes registry in the Russian Federation: dynamics of major epidemiological characteristics for 2013-2016. Diabetes Mellit 2018;20:392-402.

12. Hathout EH, Beeson WL, Ischander M, Rao R, Mace JW. Air pollution and type 1 diabetes in children. Pediatr Diabetes 2006;7:81-7.

13. Lao XQ, Guo C, Chang LY, Bo Y, Zhang Z, Chuang YC, et al. Long-term exposure to ambient fine particulate matter (PM2.5) and incident type 2 diabetes: a longitudinal cohort study. Diabetologia 2019;62:759-69.

14. Liu F, Chen G, Huo W, Wang C, Liu S, Li N, et al. Associations between long-term exposure to ambient air pollution and risk of type 2 diabetes mellitus: a systematic review and meta-analysis. Environ Pollut 2019; 252:1235-45.

15. Di Ciaula A. Type I diabetes in paediatric age in Apulia (Italy): incidence and associations with outdoor air pollutants. Diabetes Res Clin Pract 2016;111:36-43.

16. Beyerlein A, Krasmann M, Thiering E, Kusian D, Markevych I, D'Orlando $\mathrm{O}$, et al. Ambient air pollution and early manifestation of type 1 diabetes. Epidemiology 2015;26:e31-2.

17. Malmqvist E, Larsson HE, Jonsson I, Rignell-Hydbom A, Ivarsson SA, Tinnerberg $\mathrm{H}$, et al. Maternal exposure to air pollution and type 1 diabetes--Accounting for genetic factors. Environ Res 2015;140:268-74.

18. Stamatouli AM, Quandt Z, Perdigoto AL, Clark PL, Kluger H, Weiss SA, et al. Collateral damage: insulin-dependent diabetes induced with checkpoint inhibitors. Diabetes 2018;67:1471-80.

19. Lockwood AH. Diabetes and air pollution. Diabetes Care 2002;25:14878.

20. Hathout EH, Beeson WL, Nahab F, Rabadi A, Thomas W, Mace JW. Role of exposure to air pollutants in the development of type 1 diabetes before and after 5 yr of age. Pediatr Diabetes 2002;3:184-8.

21. Dedov II, Shestakova MV, Vikulova OK, Zheleznyakova AV, Isakov MA. Diabetes mellitus in Russian Federation: prevalence, morbidity, mortality, parameters of glycaemic control and structure of glucose lowering therapy according to the Federal Diabetes Register, status 2017. Diabetes Mellit 2018;21:144-59.

22. American Diabetes A. Standards of medical care in diabetes--2009. Diabetes Care 2009;32 Suppl 1:S13-61.

23. LaPorte RE, Tajima N, Akerblom HK, Berlin N, Brosseau J, Christy M, et al. Geographic differences in the risk of insulin-dependent diabetes mellitus: the importance of registries. Diabetes Care 1985;8 Suppl 1:1017.

24. WHO multinational project for childhood diabetes. WHO Diamond Project Group. Diabetes Care 1990;13:1062-8.

25. Vallero DA. Fundamentals of air pollution. Amsterdam: Academic Press,
2014.

26. Elten M, Donelle J, Lima I, Burnett RT, Weichenthal S, Stieb DM, et al. Ambient air pollution and incidence of early-onset paediatric type 1 diabetes: a retrospective population-based cohort study. Environ Res 2020;184:109291.

27. Skrodeniene E, Marciulionyte D, Padaiga Z, Jasinskiene E, SadauskaiteKuehne V, Ludvigsson J. Environmental risk factors in prediction of childhood prediabetes. Medicina (Kaunas) 2008;44:56-63.

28. Patterson CC, Harjutsalo V, Rosenbauer J, Neu A, Cinek O, Skrivarhaug $\mathrm{T}$, et al. Trends and cyclical variation in the incidence of childhood type 1 diabetes in 26 European centres in the 25 year period 1989-2013: a multicentre prospective registration study. Diabetologia 2019;62:408-17.

29. Wang GZ, Zhang L, Zhao XC, Gao SH, Qu LW, Yu H, et al. The Aryl hydrocarbon receptor mediates tobacco-induced PD-L1 expression and is associated with response to immunotherapy. Nat Commun 2019;10:1125.

30. Kawabata Y, Nishida N, Awata T, Kawasaki E, Imagawa A, Shimada A, et al. Genome-wide association study confirming a strong effect of HLA and identifying variants in CSAD/lnc-ITGB7-1 on chromosome 12q13. 13 associated with susceptibility to fulminant type 1 diabetes. Diabetes 2019;68:665-75.

31. Dimakakou E, Johnston HJ, Streftaris G, Cherrie JW. Exposure to environmental and occupational particulate air pollution as a potential contributor to neurodegeneration and diabetes: a systematic review of epidemiological research. Int J Environ Res Public Health 2018;15:1704.

32. Tuomi T, Santoro N, Caprio S, Cai M, Weng J, Groop L. The many faces of diabetes: a disease with increasing heterogeneity. Lancet 2014; 383:1084-94.

33. Bowe B, Xie Y, Li T, Yan Y, Xian H, Al-Aly Z. The 2016 global and national burden of diabetes mellitus attributable to PM2.5 air pollution. Lancet Planet Health 2018;2:e301-12.

34. Jacob AM, Datta M, Kumpatla S, Selvaraj P, Viswanthan V. Prevalence of diabetes mellitus and exposure to suspended particulate matter. J Health Pollut 2019;9:190608.

35. Gale E. Epidemiology of type 1 diabetes. Diapedia 2012;13:21042.

How to cite this article: Choi HS, Kim JT, Seo JY, Linkov F, Shubnikov E, Lee HK. Correlation between total air pollutant emissions and incidence of type 1 diabetes in the Russian Federation. Clin Exp Pediatr 2021;63:525-30. https://doi.org/ 10.3345/cep.2020.01501 
Supplementary Table 1. Incidence of T1D and T2D (per 100,000) and amount of air pollutants according to each regions of Russian Federation

\begin{tabular}{|c|c|c|c|c|c|}
\hline Russian Federation & Region number & T1D $(0-14 Y)$ & T1D & $\mathrm{T} 2 \mathrm{D}$ & Emissions of air pollutants (tons) \\
\hline Total & & 14.2 & 7 & 185.2 & $31,617.2$ \\
\hline Adygea Resp & 1 & 13.6 & 4.4 & 105.4 & 61.7 \\
\hline Altai Rep & 2 & 5.2 & 7.4 & 148.7 & 33.3 \\
\hline Altai Kr & 3 & 22.1 & 9.9 & 301.9 & 448.8 \\
\hline Amur reg & 4 & 15.1 & 8.6 & 227.6 & 229.9 \\
\hline Arkhangelsk reg & 5 & 25.4 & 10.6 & 299.5 & 268.7 \\
\hline Astrakhan reg & 6 & 16.6 & 8.8 & 239.8 & 228.7 \\
\hline Bashkortostan Rep & 7 & 29.7 & 11.4 & 206.3 & 919.9 \\
\hline Belgorod reg & 8 & 10.8 & 6.6 & 219.3 & 279.4 \\
\hline Bryansk reg & 9 & 16.5 & 10 & 304.3 & 119.9 \\
\hline Buryatia Rep & 10 & 6.7 & 5.4 & 264.1 & 209.7 \\
\hline Vladimir reg & 11 & 9.8 & 6.9 & 187.5 & 151.4 \\
\hline Volgograd reg & 12 & 10.1 & 5.9 & 192.1 & 441.7 \\
\hline Vologda reg & 13 & 12.8 & 10.8 & 171.5 & 567.1 \\
\hline Voronezh reg & 14 & 22.5 & 10.7 & 329.3 & 326.8 \\
\hline Dagestan Rep & 15 & 2.0 & 2.6 & 62.1 & 254.2 \\
\hline Jewish Aut. Ok & 16 & NA & 1.8 & 118.6 & 34.5 \\
\hline Zabaykalsky Kr & 17 & 16.9 & 4.5 & 93.4 & 239.9 \\
\hline Ivanovo reg & 18 & 15.4 & 9.5 & 287.7 & 121.1 \\
\hline Ingushetia Rep & 19 & 3.0 & 5.1 & 132.4 & 31.7 \\
\hline Irkutsk reg & 20 & 16.3 & NA & NA & 845.0 \\
\hline Kabardino-Balkar Rep & 21 & 4.6 & 4.2 & 69.4 & 86.9 \\
\hline Kaliningrad reg & 22 & 1.9 & 3.5 & 78.9 & 122.0 \\
\hline Kalmykia Rep & 23 & 5.2 & 2.5 & 162.2 & 38.2 \\
\hline Kaluga reg & 24 & 20.8 & 7.7 & 214.2 & 134.7 \\
\hline Kamchatka Kr & 25 & 27.3 & 9.2 & 216.7 & 81.3 \\
\hline Karachay-Cherkess Rep & 26 & 9.8 & 5.3 & 113.1 & 53.8 \\
\hline Karelia Rep & 27 & 19.7 & 14 & 243.5 & 205.0 \\
\hline Kemerovo reg & 28 & 16.1 & 8.5 & 168.6 & 1.577 .3 \\
\hline Kirov reg & 29 & 23.3 & 8.4 & 351.5 & 214.5 \\
\hline Komi Rep & 30 & 15.5 & 9.3 & 269.9 & 653.4 \\
\hline Kostroma reg & 31 & 27.2 & 10.6 & 229.6 & 115.6 \\
\hline Krasnodar Kr & 32 & 19.5 & 7.3 & 203 & 806.9 \\
\hline Krasnoyarsk Kr & 33 & NA & 14.3 & 210.2 & 2.632 .7 \\
\hline Crimea Rep & 34 & 7.3 & 4.2 & 119.7 & 67.0 \\
\hline Kurgan reg & 35 & 14.9 & 6.6 & 268.2 & 103.6 \\
\hline Kursk reg & 36 & 11.0 & 5.5 & 204.9 & 135.8 \\
\hline Leningrad reg & 37 & 6.4 & 5.8 & 117 & 431.6 \\
\hline Lipetsk reg & 38 & 7.2 & 7 & 115.6 & 457.2 \\
\hline Magadan reg & 39 & 19.5 & 9.6 & 165.4 & 59.7 \\
\hline Mari El Rep & 40 & 14.5 & 5.7 & 293.1 & 93.9 \\
\hline Mordovia Rep & 41 & 20.8 & 8.2 & 217.1 & 114.8 \\
\hline Moscow & 42 & 12.6 & 6.4 & 264.9 & $1,042.1$ \\
\hline Moscow reg & 43 & 22.9 & 7.8 & 179.2 & $1,026.9$ \\
\hline Murmansk reg & 44 & 13.7 & 6.8 & 162.7 & 292.1 \\
\hline Nenets AOk & 45 & NA & 11.4 & 123.2 & 91.4 \\
\hline Nizhny Novgorod reg & 46 & 22.1 & 9.3 & 256.2 & 451.4 \\
\hline Novgorod reg & 47 & 14.1 & 4.9 & 165 & 119.0 \\
\hline Novosibirsk reg & 48 & 21.3 & 8.8 & 183.3 & 479.3 \\
\hline Omsk reg & 49 & 18.4 & 10.7 & 183.4 & 385.7 \\
\hline
\end{tabular}


Supplementary Table 1. Continued

\begin{tabular}{|c|c|c|c|c|c|}
\hline Russian Federation & Region number & T1D (0-14 Y) & T1D & $\mathrm{T} 2 \mathrm{D}$ & Emissions of air pollutants (tons) \\
\hline Orenburg reg & 50 & 21.5 & 9.9 & 289.3 & 788.0 \\
\hline Oryol reg & 51 & NA & 1.3 & 83.3 & 125.4 \\
\hline Penza reg & 52 & 15.1 & 8.6 & 221.9 & 156.4 \\
\hline Perm reg & 53 & 14.4 & 8.7 & 211.7 & 610.5 \\
\hline Primorsky Kr & 54 & 15.3 & 9 & 75.9 & 425.4 \\
\hline Pskov reg & 55 & 10.2 & 5.9 & 99.6 & 127.1 \\
\hline Rostov reg & 56 & 17.6 & 6.6 & 227.7 & 629.2 \\
\hline Ryazan reg & 57 & NA & NA & NA & 222.1 \\
\hline Samara reg & 58 & 15.9 & 7.8 & 225.1 & 566.9 \\
\hline St. Petersburg & 59 & NA & 3 & 115.9 & 530.2 \\
\hline Saratov reg & 60 & NA & 1.8 & 124.2 & 368.2 \\
\hline Sakha/Yakutia/Rep & 61 & 0.9 & 3.9 & 104.1 & 330.3 \\
\hline Sakhalin reg & 62 & NA & 9.9 & 278.7 & 138.3 \\
\hline Sverdlovsk reg & 63 & 15.7 & 10.5 & 267 & $1,336.8$ \\
\hline North Ossetia-Alania Rep & 64 & 13.8 & 7.5 & 94.4 & 81.6 \\
\hline Smolensk reg & 65 & 2.9 & 7.5 & 179.1 & 143.0 \\
\hline Stavropol reg & 66 & 8.6 & 4.1 & 117.3 & 351.5 \\
\hline Tambov reg & 67 & NA & NA & NA & 159.2 \\
\hline Tatarstan Rep & 68 & 17.3 & 8.1 & 190.3 & 661.3 \\
\hline Tver reg & 69 & 2.0 & 5.7 & 165.1 & 200.4 \\
\hline Tomsk reg & 70 & 14.3 & 8.4 & 224.3 & 405.4 \\
\hline Tula reg & 71 & 12.6 & 11.2 & 264.2 & 337.4 \\
\hline Tyva Rep & 72 & NA & NA & NA & 36.0 \\
\hline Tyumen reg & 73 & 17.4 & 5.9 & 244.4 & 297.7 \\
\hline Udmurt Rep & 74 & NA & 11.4 & 213.3 & 277.6 \\
\hline Ulyanovsk reg & 75 & 16.9 & 7.2 & 203.4 & 147.0 \\
\hline Khabarovsk Kr & 76 & 11.8 & 5 & 109 & 262.2 \\
\hline Khakassia Rep & 77 & 2.8 & 4.7 & 267.9 & 138.5 \\
\hline KhMAO - Ugra AOk & 78 & 11.1 & 9 & 227 & $1,658.5$ \\
\hline Chelyabinsk reg & 79 & 10.7 & 8 & 225.4 & 905.8 \\
\hline Chechen Rep & 80 & 1.1 & 1.6 & 53.5 & 131.4 \\
\hline Chuvash Rep & 81 & 11.4 & 5 & 164.7 & 115.1 \\
\hline Chukotka AOk & 82 & NA & 14 & 217.3 & 27.6 \\
\hline Yamalo-Nenets AOK & 83 & 23.3 & 6.9 & 211 & 834.1 \\
\hline Yaroslavl reg & 84 & 25.5 & 13.1 & 323.1 & 193.5 \\
\hline
\end{tabular}

T1D, type 1 diabetes; T2D, type 2 diabetes; NA, not available. 